\title{
Serological, virological and histopathological study of an outbreak of sleeping disease in farmed rainbow trout Oncorhynchus mykiss
}

\author{
D. A. Graham ${ }^{1, *}$, H. L. Jewhurst ${ }^{2}$, M. F. McLoughlin ${ }^{3}$, E. J. Branson ${ }^{4}$, K. McKenzie ${ }^{5}$, \\ H. M. Rowley ${ }^{1}$, D. Todd ${ }^{1}$ \\ ${ }^{1}$ Department of Agriculture and Rural Development, Veterinary Sciences Division, Stoney Road, Stormont, Belfast BT4 3SD, UK \\ ${ }^{2}$ Department of Veterinary Sciences, The Queen's University of Belfast, Stoney Road, Stormont, Belfast BT4 3SD, UK \\ ${ }^{3}$ Aquatic Veterinary Services, 25 Cherryvalley Park, Belfast BT5 6PN, UK \\ ${ }^{4}$ Red House Farm, Llanvihangel, Ystern Llewern, Monmouth NP25 5HL, UK \\ ${ }^{5}$ Skretting, Wincham, Northwich, Cheshire CW9 6DF, UK
}

\begin{abstract}
A prospective longitudinal survey for sleeping disease (SD) was carried out over a 20 wk period on a caged freshwater population of farmed rainbow trout Oncorhynchus mkyiss. Pancreas, heart and red and white skeletal muscle were examined histologically and the presence and severity of lesions recorded. Sera were tested for viraemia with Salmonid Alphavirus (SAV) and for virus neutralizing (VN) antibodies. Viraemia was detected for $4 \mathrm{wk}$, beginning at Week 6 and with a peak prevalence of $57.9 \%$ at Week 7. Clinical signs and mortalities appeared at Week 8. Total mortality in the study cage from Week 6 onward was $6.3 \%$, but other cages at the site had mortality levels of up to $47.2 \%$. VN antibodies were first detected at Week 9 , with seroprevalence increasing to $80 \%$ by the end of the study (Week 20). Geometric mean antibody titres peaked at 1/89.4 at Week 17. Histological lesions were first detected at Week 7 (pancreas only), before increasing in prevalence and severity to peak at Weeks 9 and 10. The majority of lesions were resolved by Week 15.
\end{abstract}

KEY WORDS: Sleeping disease - Rainbow trout · Longitudinal survey · Antibody · Viraemia • Histopathology

Resale or republication not permitted without written consent of the publisher

\section{INTRODUCTION}

Sleeping disease (SD) is an infectious condition of farmed rainbow trout caused by sleeping disease virus (SDV) (Boucher et al. 1994, Castric et al. 1997). SDV is now recognised to be an atypical alphavirus closely related to salmon pancreas disease virus (SPDV), the cause of pancreas disease (PD) in Atlantic salmon Salmo salar L. (Villoing et al. 2000). Subsequent immunological and molecular comparison of isolates have shown that both SDV and SPDV in fact represent different strains of the same virus, for which the name salmonid alphavirus (SAV) has been proposed (Weston et al. 2002, 2006). Histologically, both SD and PD are characterized by the sequential development of pancreatic and cardiomyocytic necrosis and skeletal myopathy (Murphy et al. 1992, Boucher \& Baudin Laurencin 1996, McLoughlin et al. 1996, Weston et al. 2002). The characteristic 'sleeping' behaviour of rainbow trout with SD is considered primarily to be a consequence of the skeletal muscle damage, which particularly affects the red muscle fibres (Castric et al. 1997). Mortality rates in outbreaks are variable, ranging from 3 to $22 \%$ (Graham et al. 2003a).

Although SD has been present in farmed freshwater trout in Europe for many years, it was first reported in the UK in 2002, when outbreaks occurred in both England and Scotland (Branson 2002, Graham et al. 2003a). Although histopathology has been the standard tool used for diagnosis of SD, additional tools 
including serological tests for virus neutralizing antibodies and the rapid isolation of virus from the serum of viraemic fish are also now available (Graham et al. 2003b, Jewhurst et al. 2004). A recent study has described the comparative performance of such a diagnostic panel in fish infected by inoculation with SD at a single time point under experimental conditions (Kerbart Boscher et al. 2003). However, there are no comparable published studies from field outbreaks of either SD or PD, where fish are infected by a natural route over an extended period of time. The aim of the current study was therefore to apply this diagnostic panel to a prospective longitudinal survey of a farmed rainbow trout population experiencing an outbreak of $\mathrm{SD}$, in order to gain a better understanding of both the comparative performance of these tests at different stages of the outbreak and of the epidemiology of such outbreaks.

\section{MATERIALS AND METHODS}

Farm details and collection of samples. Samples were collected from a UK farm, which had experienced problems with SD in previous production cycles, of fish held in a 10 cage block in a freshwater loch. Each year, the farm introduced multiple batches of rainbow trout fingerlings to these cages for on-growing. Sampling at the site was targeted at 1 particular cage of fish (designated C10). On 28 April 2004 (Week 0), cage C10 was stocked with $76000,15 \mathrm{~g}$ rainbow trout fingerlings from an external source. Fish from this cage were sampled on arrival, and then regularly at 7 to $14 \mathrm{~d}$ intervals until mid-August, when this and 2 adjacent cages, C8 and C9, which had been stocked within a few days of and from the same source as $\mathrm{C} 10$, were graded. Thereafter, sampling continued to the end of September in the cage receiving the medium grades. On each sampling occasion, blood was collected into serum gel tubes (Sarstedt) from each of 20 fish. The tubes were then centrifuged to separate serum from cells. If not being shipped on the day of collection, serum was removed and frozen. In addition, pancreas, heart and red and white skeletal muscle samples were taken from 6 fish on each sampling occasion and transferred into $10 \%$ neutral buffered formalin for subsequent histopathological examination. Water temperature data and information on feed intake, mortalities and clinical signs of disease for $\mathrm{C} 10$ and 2 other cages (C2 and $\mathrm{C} 4$ ) were retrieved from the farm records. $\mathrm{C} 2$ and C4 were stocked with 102000 and 88000 fingerlings $(15 \mathrm{~g})$ the week after $\mathrm{C} 10$.

Histopathology. Tissues for histology were processed by standard paraffin wax techniques and stained with haematoxylin and eosin (H\&E) for exami- nation. Tissues from each sample point were examined and the presence or absence of SD-related lesions recorded. When present, the severity of tissue lesions was semi-quantified using an ordinal scale from 1 to 3 (mild to severe) according to a previously described scoring system, and the mean lesion score for each tissue calculated (McLoughlin et al. 2006).

Virological and serological testing. Virus neutralization testing and screening for viraemia were performed as previously described (Graham et al. 2003b, Jewhurst et al. 2004). Briefly, sera were initially screened in duplicate at dilutions of $1 / 20$ and 1/40 for virus neutralizing (VN) antibodies in a microtitrebased test, read after $3 \mathrm{~d}$ using a SAV-specific monoclonal antibody (2D9; Welsh et al. 2000) and an immunoperoxidase-based staining method. For those sera in which neutralizing endpoints were not reached on initial screening, doubling dilution series from 1/20 to $1 / 1280$ were prepared and tested in duplicate. In parallel with the VN screen, sera were inoculated into chinook salmon embryo-214 (CHSE) cells and stained after $3 \mathrm{~d}$ to identify growth of SAV. Where viraemic sera were identified, their $50 \%$ tissue culture infectious dose $\left(\mathrm{TCID}_{50}\right)$ was determined by endpoint titration in microtitre. All titres were determined according to the method of Karber (1931).

\section{RESULTS}

\section{Clinical observations and farm management}

SD-related mortalities were first recorded at the site at Week 6 (15 June 2004) of the study when clinical signs of $\mathrm{SD}$ were observed in cages $\mathrm{C} 2$ and $\mathrm{C} 4$. The first sign of onset was the appearance of occasional good-condition fish on the water surface around the sides of the pen, where there would normally only be runts, with a coincident slight fall in appetite. Almost immediately after this, large numbers of apparently good-condition fish were found in the sock in the bottom of the cage used for collecting mortalities. Many of these were dead, but some were still alive yet moribund. Some of the moribund fish would swim away when disturbed. Associated with this, weekly mortality rates in $\mathrm{C} 2$ rose from $1.3 \%$ of input in Week 5 to $2.9 \%$ at Week 6 , before peaking at $22.9 \%$ at Week 7 (Fig. 1). Mortality figures for C4 also increased from $0.9 \%$ (Week 6) to $2.6 \%$ (Week 7), before peaking at $6.2 \%$ (Week 8, Fig. 1).

Following the appearance of $\mathrm{SD}$, these fish were moved to another cage block in an effort to prevent spread of infection. In addition, all fish in the original cage block were fasted for $2 \mathrm{~d}$ and then fed at 25 to $50 \%$ of ration for a further week. Despite this, clinical signs of SD were also noted in $\mathrm{C} 10$ at Week 8, with an 


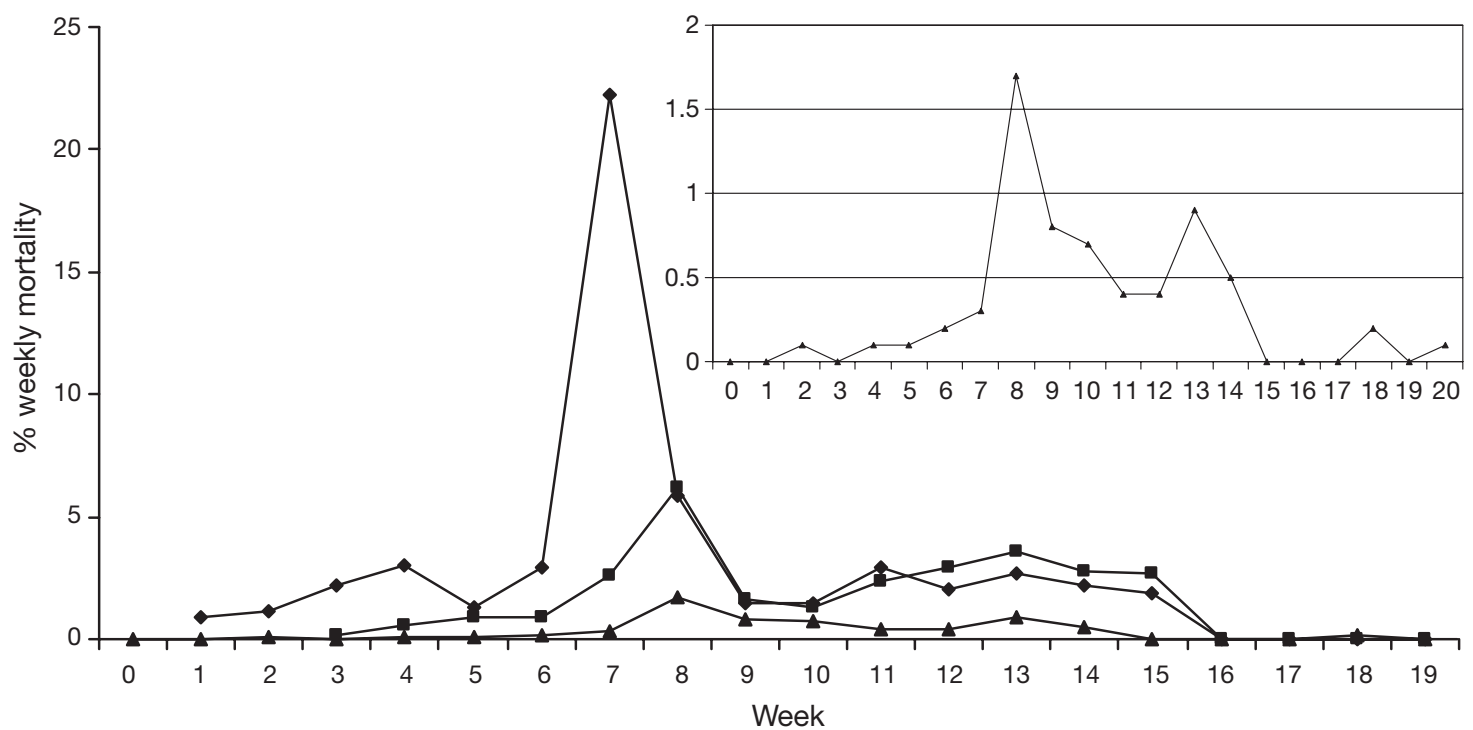

Fig. 1. Weekly mortality for C2 (•), C4 (घ) and C10 (४). Inset: C10 in more detail

increase in mortalities from $0.3 \%$ at Week 7 to a peak of $1.7 \%$ at Week 8 . SD was first reported in C8 and C9 at the same time as $\mathrm{C} 10$, with a similar mortality profile (data not shown). The mortality curves in C2, C4 and C10 showed a biphasic pattern, with a second, lower extended peak of mortality occurring 3 to $6 \mathrm{wk}$ after the first (Fig. 1). The cumulative mortalities in these cages following the appearance of SD were very variable, ranging from a maximum of $47.2 \%$ (C2) to $6.3 \%$ (C10), with an intermediate value of $28.0 \%$ for C4. Water temperatures over the sampling period varied between $7.8^{\circ} \mathrm{C}$ at the start of sampling and $14.5^{\circ} \mathrm{C}$ at the end, with a peak of $16^{\circ} \mathrm{C}$ at Week 16. Temperatures during Weeks 6 to 10, the period of peak mortality, were in the range of $12.5^{\circ} \mathrm{C}$ to $13.5^{\circ} \mathrm{C}$.

\section{Histopathology}

Illustrative examples of the histological changes observed in pancreas, heart, red muscle (RM) and white muscle (WM) are shown in Fig. 2. Histological evidence of SD was first detected in C10 at Week 7, when acute pancreatic acinar cell necrosis of moderate severity was observed in a single fish of the 6 sampled (Table 1). No lesions were observed in the other tissues from this fish, or in any of the remaining fish. At Week 8, the pancreatic acinar cells in all fish appeared normal, with mild inflammation only and no significant atrophy. Acute multifocal myocardial cell degeneration was evident in 2 fish, with both layers of the heart affected. Mild multifocal myofibrillar degeneration with surrounding inflammation was present in the RM of 3 of 6 fish. These were considered representative of sub-acute to chronic lesions (McLoughlin et al. 2002). At Week 9, the pancreas of 1 fish was recovering, while the remainder appeared normal, suggesting very mild

Table 1. Oncorhynchus mykiss. Summary of histological, virological and serological findings, showing no. of fish with lesions in each tissue at each time point, the \% of viraemic and seropositive fish, and the corresponding geometric mean titres $(\mathrm{GMT})$ of virus $\left(\log _{10}\right)$ and antibody (reciprocal). Pan: pancreas; WM: white muscle; RM: red muscle; ND: not determined

\begin{tabular}{|c|c|c|c|c|c|c|c|c|c|}
\hline \multirow[t]{2}{*}{ Week } & \multicolumn{4}{|c|}{$\longrightarrow$ Histology } & \multicolumn{2}{|c|}{ Virus } & \multicolumn{3}{|c|}{ Antibody } \\
\hline & Pan & Heart & WM & $\mathrm{RM}$ & & $\begin{array}{l}\text { GMT } \\
\text { ID }_{50} \mathrm{ml}^{-1} \text { ) }\end{array}$ & $\%$ & GMT & Max. titre \\
\hline 0 & ND & ND & ND & ND & 0 & - & 0 & - & $<20$ \\
\hline 1 & ND & ND & ND & ND & 0 & - & 0 & - & $<20$ \\
\hline 2 & ND & ND & ND & ND & 0 & - & 0 & - & $<20$ \\
\hline 3 & ND & ND & ND & ND & 0 & - & 0 & - & $<20$ \\
\hline 4 & ND & ND & ND & ND & 0 & - & 0 & - & $<20$ \\
\hline 5 & 0 & 0 & 0 & 0 & 0 & - & 0 & - & $<20$ \\
\hline 6 & 0 & 0 & 0 & 0 & 35 & 7.1 & 0 & - & $<20$ \\
\hline 7 & 1 & 0 & 0 & 0 & 57.9 & 7.5 & 0 & - & $<20$ \\
\hline 8 & 3 & 2 & 2 & 3 & 20 & 7.8 & 0 & - & $<20$ \\
\hline 9 & 1 & 5 & 6 & 6 & 20 & 6.6 & 5 & 20 & 20 \\
\hline 10 & 1 & 5 & 3 & 3 & 0 & - & 20 & 40 & 80 \\
\hline 11 & 0 & $3^{a}$ & 0 & 3 & 0 & - & 65 & 43.4 & 120 \\
\hline 13 & 0 & 1 & 2 & 1 & 0 & - & 68.4 & 68.5 & 160 \\
\hline 15 & 0 & 0 & 0 & 0 & ND & ND & ND & ND & ND \\
\hline 17 & 1 & 2 & 0 & 0 & 0 & - & 60 & 89.4 & 320 \\
\hline 19 & 0 & 0 & 0 & 0 & ND & ND & ND & ND & ND \\
\hline 20 & 0 & 2 & 0 & 1 & 0 & - & 80 & 46.3 & 640 \\
\hline
\end{tabular}



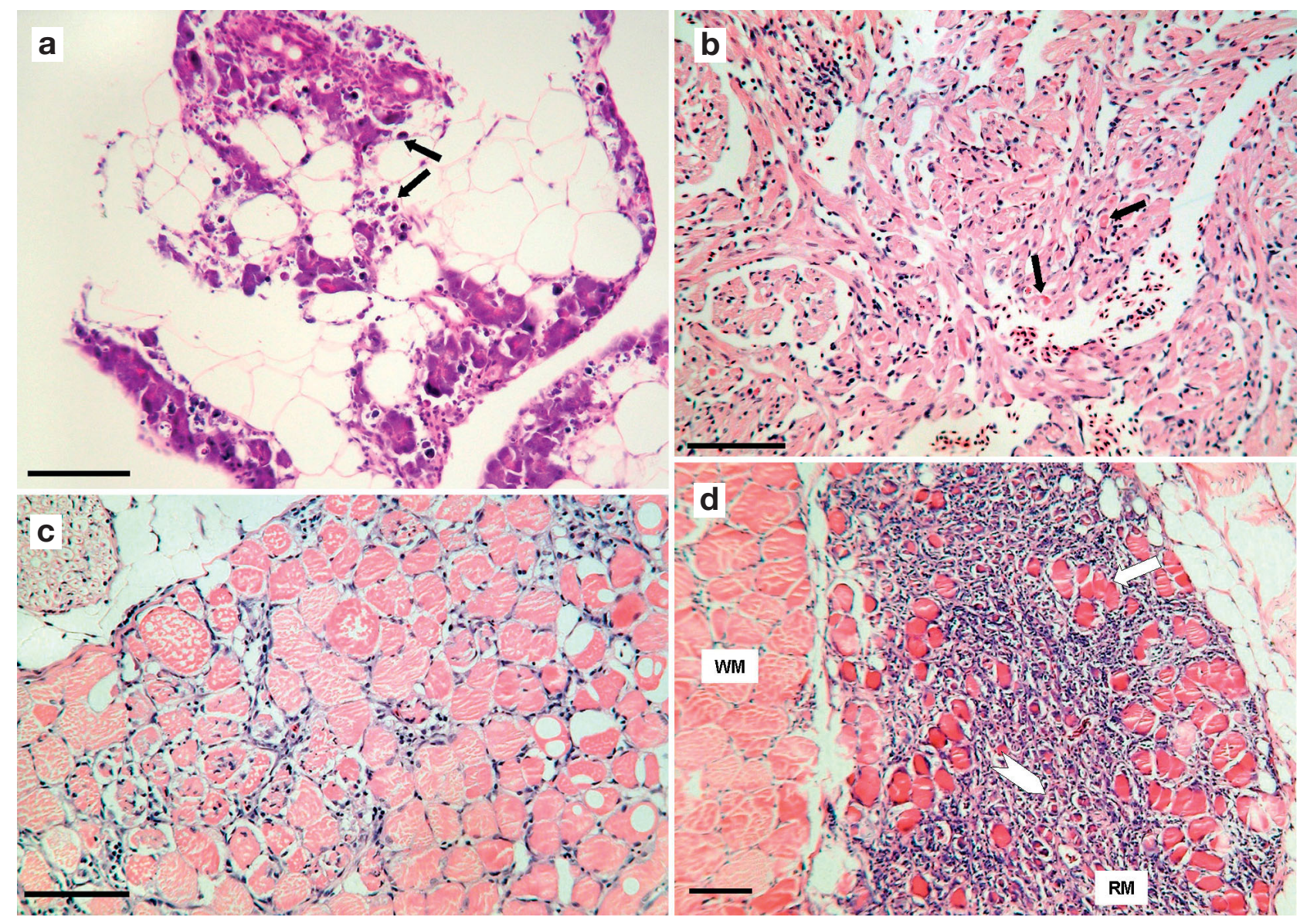

Fig. 2. (a) Acute pancreatic acinar cell necrosis (arrows), typical of acute sleeping disease. (b) Acute focal myocardial necrosis (arrows), typical of early sleeping disease. (c) Acute red muscle (aerobic type 1) fibre degeneration, with vacuolation, phagocytosis and centralization of nuclei. (d) Severe skeletal muscle degeneration and fibrosis of the lateral line red muscle fibres (aerobic type 1 ; open arrow) with some surviving red muscle fibres (open arrow). RM: red muscle; WM: white muscle. Scale bar = $100 \mu \mathrm{m}$

pancreatic lesions or rapid recovery. However, 5 of 6 fish had moderate sub-acute to chronic myocarditis, and all had mild to moderate RM and WM degeneration typical of chronic SD. At Week 10, a similar picture was evident. All fish had mild to moderate focal chronic myocarditis, and 3 of 6 had moderate to severe RM degeneration and inflammation and mild focal WM degeneration. At Week 11, a very variable pattern was apparent, consistent with the recovery phase of $\mathrm{SD}$. The pancreas in all fish appeared normal.

Low-grade focal inflammation was present in 3 of 4 hearts examined. There was no obvious WM pathology, and the RM was mild to severely damaged in 3 of 6 fish. At Week 13, 4 fish had no significant histological lesions. One fish had mild chronic lesions in the heart, $\mathrm{RM}$ and WM, consistent with chronic SD, and one had moderate WM lesions. At Week 15, there was no evidence of SD in any fish. At Week 17 there was a total absence of pancreatic acinar tissue in 1 fish, indicating failure of pancreatic recovery. One other fish had mild focal insignificant inflammation of the ventricle, and another diffuse epicarditis with associated myocarditis. No skeletal muscle lesions were detected. At Week 19 there was no evidence of sleeping disease in any samples. At Week 20, 2 fish had low-grade focal inflammation in the spongy ventricular tissue and another had focal RM fibre inflammation.

Examination of the prevalence data (Table 1) and mean lesion scores (Fig. 3) reveals a typical pattern associated with SD and SPDV (McLoughlin et al. 2002), with sequential development of lesions in the pancreas, heart and red and white skeletal muscle fibres.

\section{Virology}

Viraemic fish were first detected in C10 at Week 6, $2 \mathrm{wk}$ in advance of clinical signs and $1 \mathrm{wk}$ in advance of the first histological evidence of infection. At this point, $35 \%$ of serum samples were viraemic (Table 1). Viraemic 


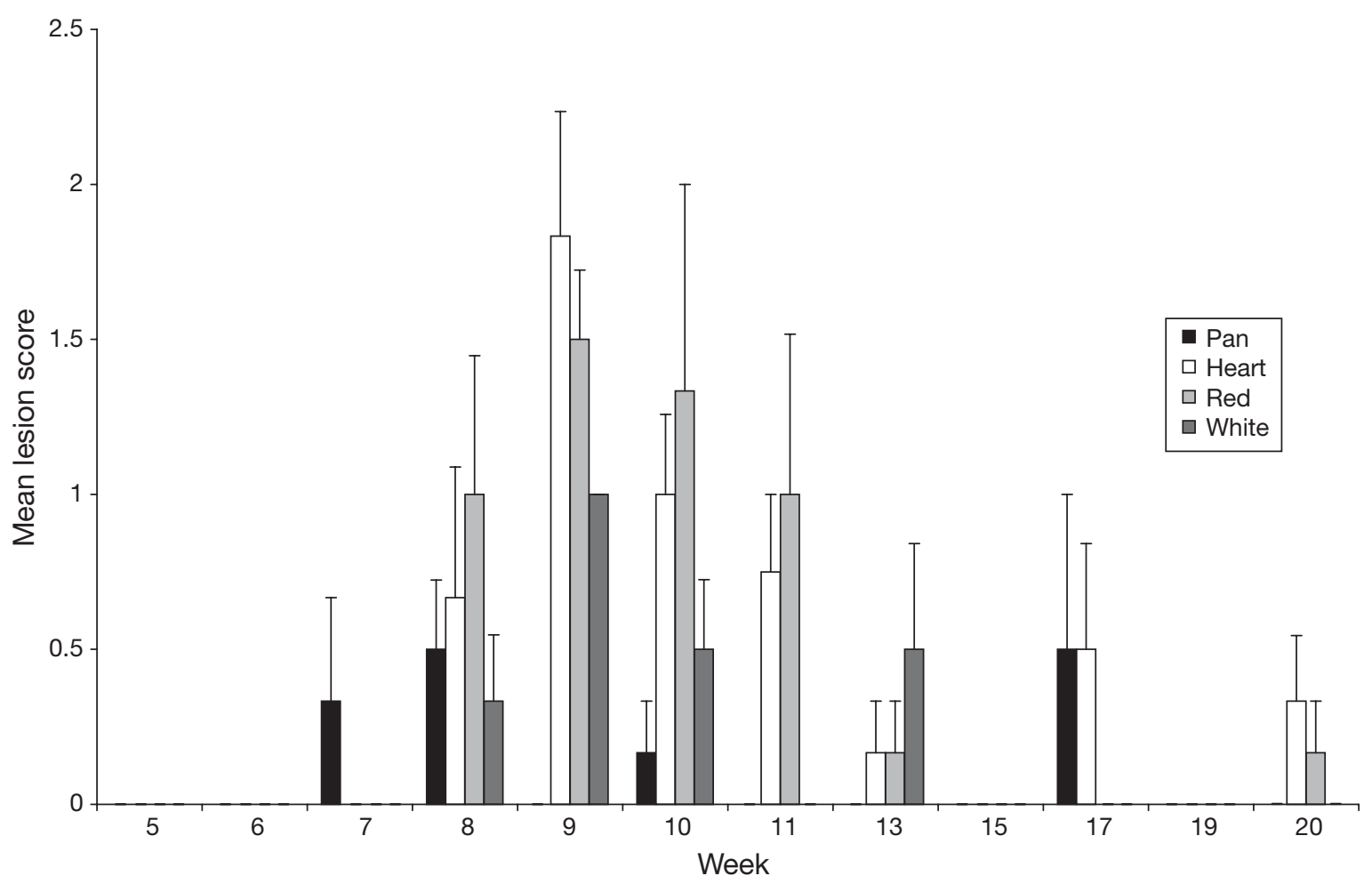

Fig. 3. Mean lesion scores (+SE) for pancreas (Pan), heart and red and white skeletal muscle for Weeks 5 to 20

sera were also detected in each of the next 3 weeks, with prevalence figures of 57.9, 20 and $20 \%$. The peak of viraemia preceded the onset of clinical signs by $1 \mathrm{wk}$. No viraemic sera were detected from Week 10 onwards. The geometric mean titre of the viraemic sera ranged from $10^{6.6} \mathrm{TCID}_{50} \mathrm{ml}^{-1}$ to $10^{7.8} \mathrm{TCID}_{50} \mathrm{ml}^{-1}$ (Table 1).

\section{Serology}

VN antibodies were first detected at Week 9, $3 \mathrm{wk}$ after first detection of viraemia (Table 1 ) and $1 \mathrm{wk}$ after clinical signs were reported, when a single serum (5\%) tested positive for antibody. Thereafter, the seroprevalence increased steadily to a peak of $80 \%$ at Week 20 . Mean GM titres followed a similar profile, rising from $1 / 20$ at Week 9 to a peak of 1/89.4 at Week 17, before declining to $1 / 46.3$ at Week 20. Similarly, the maximum titre recorded rose from $1 / 20$ at Week 9 to $1 / 640$ at Week 20.

\section{DISCUSSION}

This study is the first published description of the sequential changes in histopathological, virological and serological findings associated with a natural outbreak of sleeping disease in Oncorhynchus mykiss. SD was diag- nosed in fish in cages C2 and C4 approximately 6 wk after their introduction and then spread through the cage block, with clinical signs observed in all remaining stocked cages within a $7 \mathrm{wk}$ period. The source of the infection remains unknown. Although the fingerlings were obtained from several different sources, there were no reports of SD on their farms of origin; however, the fish themselves or contaminated equipment associated with their movement or other management activities cannot be ruled out as possible vectors. When the fingerlings were introduced, there were still older fish at the site that were survivors of an earlier outbreak of SD. Although an epidemiologically significant carrier state has yet to be demonstrated for SAV, these fish represent another possible source of infection. The presence of wild fish and previously escaped SAV-seropositive fish in the vicinity of the cages (authors' unpubl. data) represent other possible sources.

Because the trial had to take place within the constraints of normal management, the sample population was graded during the trial period. The fact that these fish were graded and mixed with others from adjacent cages that had been stocked within a few days of, and from the same source as, the sampled population, and that had first shown clinical signs on the same day and had suffered similar relatively low levels of mortality, is considered to have minimized any bias in sampling post-grading. 
The development of the histopathological lesions seen in $\mathrm{C} 10$ reflect the pattern seen in experimental infections with both SDV and SPDV (Boucher \& Baudin Laurencin 1996, McLoughlin et al. 1996, Kerbart Boscher et al. 2003). Thus, at Week 7, the only observation was of acute pancreatic acinar cell necrosis in a single fish (Table 1, Fig. 2a). Thereafter, cardiac and skeletal muscle lesions predominated, with lesions particularly prevalent and severe from Weeks 8 to 11 . Thereafter, cardiac and skeletal muscle lesions were seen intermittently until Week 20, indicating that lesions in some fish can take several months to fully resolve. The peak prevalence and severity of cardiac and skeletal muscle lesions at Week 9, 1 wk after the appearance of clinical signs, demonstrates the usefulness of histology as a diagnostic tool in such cases. Nevertheless, it is noteworthy that viraemia was detectable at Week 6, 2 wk in advance of the onset of clinical signs, and 1 wk before the first histopathological changes were detected (Table 1). This delay between initial detection of viraemia and development of clinical signs indicates a $2 \mathrm{wk}$ lag period between infection and development of lesions of sufficient severity to produce visible effects. These results demonstrate the usefulness of screening for viraemia in order to detect the presence of infection as an early warning of disease, allowing management to take appropriate measures. These include the avoidance of stressors such as grading and moving, which may help to reduce mortalities and onward spread of infection.

Although variable, the extent of mortalities recorded in this outbreak highlight the potential economic impact of the disease. The reasons for the variable mortality among cages is unknown. However, stress is a recognised risk factor for disease (McLoughlin et al. 2003), and the movement of fish in C2 and C4 during the outbreak is likely to have contributed to the losses in these cages. While the mechanism is unknown, there is evidence from this study that restricting food intake in the face of an outbreak might reduce mortalities, because the fasting of all cages and a gradual return to full feed coincided with the onset of viraemia in $\mathrm{C} 10$. This may have contributed to the significantly lower mortalities in cages C8, C9 and C10 when compared with cages $\mathrm{C} 2$ and $\mathrm{C} 4$, which were only subjected to the same dietary regime once clinical symptoms were seen. It is recognised that the additional factors in $\mathrm{C} 2$ and $\mathrm{C} 4$ described above complicate the interpretation of these events, and further studies will be required to confirm or refute this observation.

In this study, infection spread quickly through the study population, with a peak of $65 \%$ of viraemic fish present at Week 7 followed by a clearance of viraemia by Week 10. This implies an efficient mechanism of transfer of virus within the population. The relatively high titres of virus present in these fish during this period, if reflected in the levels of virus shed into the water within the cage, would provide such a mechanism.

VN antibodies were first detected at Week $9(5 \%)$, 3 wk after viraemia was first detected and overlapping with the last week of viraemia. This interval between infection and seroconversion is consistent with what has been described previously under experimental conditions (McLoughlin et al. 1996, Desvignes et al. 2002, Kerbart Boscher et al. 2003). Thereafter, the seroprevalence increased rapidly, reaching a plateau of 60 to $80 \%$, which was maintained over several months to the end of the study period (Week 20); however, by this time, the geometric mean titre (GMT) of VN antibodies had peaked and started to decline. This serological response is considered to reflect a longterm protection against a future recurrence of clinical disease (Houghton 1994, Boucher \& Baudin Laurencin 1996). This pattern is similar to that previously reported for natural outbreaks of pancreas disease in Atlantic salmon (Graham et al. 2005). The current use of serology for diagnostic and epidemiological investigations of fish diseases is limited and contrasts markedly with the situation in avian and mammalian medicine. Although there are valid reasons for this (Denzin \& Staak 2000), the results presented here show that the methodology can still be applied effectively to demonstrate that a population has undergone infection, even after viraemia has been cleared and histological lesions resolved.

In conclusion, the results presented in this study show for the first time the comparative chronological development of histological lesions, viraemia and neutralizing antibody responses associated with a natural outbreak of sleeping disease in rainbow trout. The data indicate that viraemia precedes both the onset of histological changes and clinical signs, and that VN antibodies persist and may be used to retrospectively detect infection for some time afterwards. These findings provide useful information with regard to the epidemiology of natural infection, sampling strategies and interpretation of results.

Acknowledgements. This study was partly funded by EU project QLK2-CT-2001-000970 (Diagnoses, pathogeneses and epidemiologies of salmonid alphavirus diseases). This manuscript is dedicated to the memory of Edward Branson, who passed away in 2006.

\section{LITERATURE CITED}

Boucher P, Castric J, Baudin Laurencin F (1994) Observation of virus like particles in rainbow trout Oncorhynchus mykiss infected with sleeping disease virulent material. Bull Eur Assoc Fish Pathol 14:215-216

Boucher P, Baudin Laurencin F (1996) Sleeping disease and 
pancreas disease: comparative histopathology and acquired cross-protection. J Fish Dis 19:303-310

Branson E (2002) Sleeping disease in trout. Vet Rec 150: $759-760$

Castric J, Baudin Laurencin F, Brémont M, Jeffroy J, Le Ven A, Béarzotti M (1997) Isolation of the virus responsible for sleeping disease in experimentally infected rainbow trout (Oncorhynchus mykiss). Bull Eur Assoc Fish Pathol 17: $27-30$

Denzin N, Staak C (2000) Fish immunoglobulin - a serodiagnostician's perspective. Bull Eur Assoc Fish Pathol 20: $60-64$

Desvignes L, Quentel C, Lamour F, Le Ven A (2002) Pathogenesis and immune response in Atlantic salmon (Salmo salar L.) parr experimentally infected with salmon pancreas disease virus (SPDV). Fish Shellfish Immunol 12: 77-95

Graham DA, Rowley HM, Walker IW, Weston JH, Branson EJ, Todd D (2003a) First isolation of sleeping disease virus from rainbow trout, Oncorhynchus mykiss (Walbaum) in the United Kingdom. J Fish Dis 26:691-694

Graham DA, Jewhurst VA, Rowley HM, McLoughlin MF, Todd D (2003b) A rapid immunoperoxidase-based virus neutralization assay for salmonid alphavirus. J Fish Dis 26:407-413

Graham DA, Jewhurst VA, Rowley HM, McLoughlin MF, Rodger H, Todd D (2005) Longitudinal serological surveys of Atlantic salmon (Salmo salar L.) using a rapid immunoperoxidase-based neutralization assay for salmonid alphavirus. J Fish Dis 28:373-379

Houghton G (1994) Acquired protection in Atlantic salmon Salmo salar parr and post-smolts against pancreas disease. Dis Aquat Org 18:109-118

Jewhurst VA, Todd D, Rowley HM, Walker IW, Weston JH, McLoughlin MF, Graham DA (2004) Detection and antigenic characterization of salmonid alphavirus isolates from sera obtained from farmed Atlantic salmon, Salmo salar L., and farmed rainbow trout, Oncorhynchus mykiss (Walbaum). J Fish Dis 27:143-149

Karber G (1931) Beitrag zur kollektiven Behandlung pharmakologischer Reihenversuche. Arch Exp Pathol Pharmakol 162:480-483

Kerbart Boscher S, McLoughlin M, Le Ven A, Cabon J, Baud M, Castric J (2003) Experimental transmission of sleeping

Editorial responsibility: Jo-Ann Leong,

Kaneohe, Hawaii, USA disease in one-year-old rainbow trout, Oncorhynchus mykiss (Walbaum), induced by sleeping disease virus. J Fish Dis 29:263-273. doi: 110.1111/j.1365-2761.2006. 00716.x

McLoughlin MF, Nelson RT, Rowley HM, Cox DI, Grant AN (1996) Experimental pancreas disease in Atlantic salmon Salmo salar post-smolts induced by salmon pancreas disease virus (SPDV). Dis Aquat Org 26:117-124

McLoughlin MF, Nelson RT, McCormick JI, Rowley HM, Bryson DB (2002) Clinical and histopathological features of naturally occurring pancreas disease in farmed Atlantic salmon, Salmo salar L. J Fish Dis 25:33-43

McLoughlin MF, Peele E, Foyle KL, Rodger HD, O'Ceallachain D, Geoghegan F (2003) An epidemiological investigation of the re-emergence of pancreas disease in Irish farmed Atlantic salmon (Salmo salar L.) in 2002. Marine Environment and Health Series No. 14. Marine Institute, Galway

McLoughlin MF, Graham DA, Norris A, Matthews D and 5 others (2006) Virological, serological and histopathological evaluation of fish strain susceptibility to experimental infection with salmonid alphavirus. Dis Aquat Org 72: 125-133

Murphy TM, Rodger HD, Drinan EM, Gannon F, Kruse P, Korting W (1992) The sequential pathology of pancreas disease in Atlantic salmon farms in Ireland. J Fish Dis 15:401-408

Villoing S, Béarzotti M, Chilmonczyk JC, Brémont M (2000) Rainbow trout sleeping disease virus is an atypical alphavirus. J Virol 74:173-183

Welsh M, Weston J, Borghmans BJ, Mackie D, Rowley H, Nelson R, McLoughlin MF, Todd D (2000) Biochemical characterization of salmon pancreas disease virus. J Gen Virol 81:813-820

Weston J, Villoing S, Brémont M, Castric J and 7 others (2002) Comparison of two aquatic alphaviruses, salmon pancreas disease virus and sleeping disease virus, by using genome sequence analysis, monoclonal reactivity, and cross-infection. J Virol 76:6155-6163

Weston JH, Graham DA, Branson E, Rowley HM, Walker IW, Jewhurst VA, Jewhurst HL, Todd D (2005) Nucleotide sequence variation in salmonid alphaviruses from outbreaks of salmon pancreas disease and sleeping disease. Dis Aquat Org 66:105-111

Submitted: October 25, 2005; Accepted: October 25, 2006 Proofs received from author(s): February 25, 2007 